\title{
A complexidade do encontro de esferas discursivas: o caso da mídia e da religião na contemporaneidade
}

Kelli da Rosa Ribeiro"

\section{Resumo}

Este artigo apresenta discussões acerca do encontro entre a esfera midiática e a esfera religiosa, observando aspectos relativos ao consumo que constituem as práticas religiosas neopentecostais na sociedade contemporânea, considerando a concepção dialógica da linguagem, desenvolvida por Bakhtin e seu Círculo. Para tanto, primeiramente, refletimos a respeito da noção de esfera discursiva, advinda dos estudos bakhtinianos, concatenando também os conceitos de enunciado e gêneros discursivos, a fim de embasar a discussão sobre o funcionamento das esferas tratadas neste artigo. Logo após, abordamos a esfera midiática em relação dialógica com a esfera religiosa, focalizando o debate no contexto dos discursos televisivos neopentecostais. $\mathrm{Na}$ análise das duas esferas em tensão, recorremos a diferentes áreas do conhecimento, a fim de explicar a complexidade envolvida na descrição do contexto que envolve os discursos neopentecostais na mídia.

Palavras-chave: Esfera discursiva. Mídia. Religião. Tensão.

\section{Palavras iniciais: problematização das esferas em jogo}

O discurso religioso contemporâneo, sobretudo o neopentecostal, tem como principal pano de fundo uma sociedade capitalista que, frequentemente, tem priorizado as relações mercadológicas em detrimento das relações humanas, de modo que as relações humanas e simbólicas passam a emergir e a ser vinculadas, necessariamente, às relações mercadológicas do consumo. Os discursos religiosos veiculados na mídia deixam reverberar os reflexos das diversas engrenagens da

\footnotetext{
Doutora em Linguística pela Pontifícia Universidade Católica do Rio Grande do Sul (PUCRS). Professora Adjunta no Instituto de Letras e Artes da Universidade Federal do Rio Grande (ILA-Furg). Membro do grupo de pesquisa Diálogos com Bakhtin (CNPq - FURG). Realiza pesquisa na área dos estudos dialógicos do discurso, em interface com a Sociologia da religião, o campo das mídias e a Filosofia. E-mail: klro.rib@gmail.com
}

\footnotetext{
Data de submissão: mar. 2017 - Data de aceite: mar. 2017 http://dx.doi.org/10.5335/rdes.v13i1.6779
} 
sociedade contemporânea, considerada por muitos filósofos como "pós-moderna".

Desse modo, parece paradoxal que uma instituição cristã, que, tradicionalmente, tem um Deus supremo que resolve todas as questões, passe a lançar mão de estratégias de Mercado em relação aos seus fiéis. Isso acontece porque, conforme explica Dufour (2008, p. 87), o Mercado corresponde a uma tentativa "de produzir um novo grande Sujeito", que ultrapasse em potência todos os antigos, entre eles o Deus soberano.

Nesse contexto, de acordo com Dufour (2005, p. 88), o Mercado apresenta atributos de divindade, uma vez que possui "onipotência contanto que o deixem realmente agir", isto é, que tenha livre acesso entre os sujeitos. Além disso, o Mercado e sua apoteose apresentam-se como a verdade e única forma de providências a que o sujeito pode recorrer. Tornam-se, então, o Mercado e também as igrejas, nessa perspectiva, espaços de trocas generalizadas, em que "fluxos se cruzam, se conectam e se desconectam". Tais fluxos são dos mais variados tipos: de energia, dinheiro, inteligência, mercadoria, forma, imagem. Acrescentaríamos, ainda, nessa lista de fluxos, a fé, que é, por vezes, comercializada, espetacularizada e colocada na esteira da possibilidade de ser adquirida, em diferentes dimensões, por meio da doação de dinheiro e adesão à doutrina (DUFOUR, 2005, p. 88).

Essa apoteose de fluxos do Mercado, então, ressalta Dufour (2005, p. 89), é reconhecida por meio de alguns aspectos, dentre os quais destacamos, primeiramente, a crença fomentada pelo "catecismo publicitário de que a salvação individual passa pelo consumo", sendo esse o grande motor do Mercado, e, depois, o aparecimento de "rebanhos de consumidores federados pelo Mercado e interpelados indivíduo por indivíduo, notadamente pela televisão".

Para Ribeiro (2015), uma das esferas mais presentes na sociedade é a esfera religiosa, que, atualmente, encontra na esfera midiática um meio bastante fértil de propagação de crenças, valores e visões de mundo. Tais esferas engendram-se e atuam ativamente na vivência e nas atitudes dos sujeitos que a elas estão expostos. Na pesquisa de Ribeiro (2015), o culto religioso da Igreja Internacional da Graça de Deus constituiu-se como foco da investigação, sendo analisado como um evento social, historicamente situado na cadeia da comunicação verbal. Por ser produzido e por circular no limiar das esferas midiática e religiosa, atingindo milhares de sujeitos, seu discurso baseado em promessas divinas acaba por arrecadar muitos adeptos e fiéis para a igreja, que são potenciais de contribuição em dinheiro para a instituição.

Pensando nessas questões e buscando verticalizar o debate proposto por Ribeiro (2015), este artigo parte do seguinte questionamento: como acontece o encontro das esferas midiática e religiosa no contexto do culto televisivo Show da fé? Para responder essa questão, procuramos discutir, com uma concepção dialó- 
gica da linguagem, acerca do encontro entre a esfera midiática e a esfera religiosa, observando os aspectos relativos ao consumo que constituem as práticas religiosas neopentecostais na sociedade contemporânea. Para tanto, realizamos a análise calcada em uma investigação qualitativa e bibliográfica, buscando, em diferentes áreas do conhecimento, subsídios para delinear as esferas em foco. Dividimos, então, as reflexões em dois momentos: no primeiro, explanamos a respeito da noção de esfera discursiva oriunda dos estudos bakhtinianos, encadeando os conceitos de enunciado e gêneros discursivos, a fim de embasar a discussão sobre o funcionamento das esferas em jogo neste artigo; no segundo, abordamos a esfera midiática em relação dialógica com a esfera religiosa, focalizando o debate no contexto dos discursos televisivos neopentecostais.

\section{O conceito de esfera discursiva: contribuições de Bakhtin}

Iniciamos esta seção tratando do que não é uma esfera ${ }^{1}$ discursiva, visando descartar ideias um tanto banalizadas sobre o tema. Nesse caso, esfera não seria um lugar físico, um ambiente empírico em si, pois sua complexidade ultrapassa as barreiras físicas dos lugares nos quais se praticam atividades diversas. Nesse sentido, partimos da ideia de que uma esfera discursiva se constitui como lugar de produção, circu- lação e recepção de discursos, de ações tipificadas de linguagem, de modos de organização dos gêneros do discurso. Assim, uma esfera revela dimensões valorativas de organização das práticas sociais, cujo foco balizador é o conteúdo temático envolvido. Uma aula, por exemplo, pode ser ministrada em um ambiente físico totalmente diferente da escola ou da universidade.

Grillo (2012, p. 147) afirma que esfera discursiva "é um espaço de refração que condiciona a relação enunciado/ objeto do sentido, enunciado/enunciado, enunciado/coenunciadores". A autora explica esse conceito a partir da teoria bakhtiniana e acrescenta que "[...] as esferas dão conta da realidade plural da atividade humana ao mesmo tempo que se assentam sobre o terreno comum da linguagem verbal humana". Essa pluralidade é condicionada e atrelada aos enunciados concretos e vivos que se constituem a partir de gêneros do discurso.

Desse modo, colocamos a discussão acerca da noção de esfera discursiva no terreno da interação verbal, possibilitada pelo universo semiótico oriundo das múltiplas práticas sociais e ideológicas. Bakhtin/Volochinov ([1929]2010, p. 33) ressalta que "cada campo da criatividade ideológica tem seu próprio modo de orientação para a realidade e refrata a realidade à sua própria maneira", visto que cada campo/esfera dispõe de uma função peculiar no conjunto do corpo social. Concordamos com Grillo (2012, p. 144) que "a onipresença social da pa- 
lavra, ou seja, a sua influência em todos os campos ideológicos (ciência, religião, literatura, etc.) confere-lhe o estatuto privilegiado para o estudo da organização dos diversos campos". A palavra é o ponto de partida da constituição das esferas discursivas e a mútua influência é ininterrupta.

A palavra, nessa direção, é tomada por Bakhtin/Volochinov ([1929]2010, p. 117) como uma "ponte lançada entre mim e os outros", servindo de "expressão a um em relação ao outro". Assim, a palavra possibilita o encontro dos sujeitos e a expressão de valores sociais que perpassam a história de uma comunidade. Desse modo, a palavra é assentada no solo da alteridade e está mergulhada no mar de relações dialógicas, sendo que tais relações é que lhe definem e que lhe dão vida.

É importante salientar que, no escopo da teoria dialógica, há vários sentidos para o termo "palavra", ou seja, pode ser tanto aparato técnico, no plano da língua, contendo significação, quanto enunciado e signo ideológico, no plano do uso da língua, contendo sentidos. Nosso interesse reside, portanto, na palavra como signo ideológico, que, no campo das enunciações, reflete e refrata diferentes sentidos, valores, posicionamentos, nas variadas situações de interação que constituem as esferas discursivas.

As palavras como signos ideológicos só adquirem sentido no contexto em que se tenha uma apreciação social de valoração. A valoração acontece em duas dimensões intrinsecamente vinculadas: a valoração individual e as valorações sociais. A valoração individual de locutores e interlocutores está encadeada com as valorações sociais circundantes. Isso acontece porque a palavra é parte de uma realidade social. Conforme explica Medviédev ([1928]2012, p. 185), é a "entonação expressiva que dá cor à palavra do enunciado", refletindo sua singularidade socio-histórica.

A avaliação social é parte essencial do processo de refração de sentidos no signo ideológico. Medviédev ([1928]2012, p. 190) afirma que a entonação "leva-nos além dos limites do enunciado para outra realidade", ou seja, "a palavra é apenas um apêndice de outra presença". Isso significa que as palavras estão necessariamente ligadas aos diversos campos sociais e aos julgamentos de valor como se fossem apêndices dessas realidades sociais. Cortando-se a palavra da sua realidade concreta, corre-se o risco de isolar seu sentido e reduzi-lo à significação de formas abstratas. É nesse sentido que Volochinov/Bakhtin ([1926]2011, p. 165) ressalta que, se a enunciação for arrancada "do chão real que a alimenta", perde-se 0 acesso de "compreensão tanto de sua forma quanto de seu sentido", restando apenas a "moldura linguística abstrata".

A relação entre palavra e acento apreciativo está impressa na obra bakhtiniana, desde as primeiras reflexões em Para uma filosofia do ato. Segundo Bakhtin ([1920] 2010a, p. 84), “a expressão do ato a partir do interior e a expressão do 
existir-evento único no qual se dá o ato exigem a inteira plenitude da palavra". $O$ autor explica que essa plenitude ocorre sob dois aspectos: o primeiro é o aspecto de conteúdo-sentido, a palavra-conceito; o segundo é o aspecto emotivo-volitivo, a entonação da palavra.

Fica claro, segundo as reflexões de Bakhtin ([1920] 2010a), que a palavra possibilita a materialização dos sentidos e das avaliações dos objetos. A palavra, desse modo, participa de forma plena da expressão de um evento e nela se reverberam as atitudes responsivas do sujeito em relação ao objeto e em relação ao outro. O filósofo ainda explica que "uma palavra realmente pronunciada não pode evitar de ser entoada, a entonação é inerente ao fato de ser pronunciada”, ou seja, a palavra imprime uma atitude avaliativa em relação ao objeto e "movimenta-o em direção do que ainda está por ser determinado por ele, torna-se momento de um evento vivo" (BAKHTIN, [1920] 2010a, p. 85-86).

O signo ideológico torna-se, conforme Bakhtin/Volochinov ([1929]2010), o lugar de valores contraditórios, ou seja, o lugar de embate entre múltiplas e diferentes vozes sociais. Os autores chegam a comparar o signo ideológico à "arena", a fim de mostrar o quanto, na linguagem, confrontam-se e entram em choque os valores sociais circundantes, os pontos de vista a respeito de determinado tema e o quanto o sujeito está envolto nesse jogo avaliativo, nos diversos contextos de interação. Por isso que, ao longo da obra do Círculo, observamos a insistência dos estudiosos em tratar dos signos ideológicos verbais e não verbais vinculados a contextos sociais.

Nessa perspectiva do construto bakhtiniano, os enunciados vivos e concretos refletem as condições específicas e as finalidades de cada referido campo não só por seu conteúdo (temático) e pelo estilo da linguagem, mas também por sua construção composicional. Segundo o pensador russo, todos esses elementos - o conteúdo temático, o estilo, a construção composicional -

[...] estão indissoluvelmente ligados no todo do enunciado e são igualmente determinados pela especificidade de um determinado campo da comunicação discursiva (BAKHTIN, 2003, p. 261).

Medviédev ([1928]2012, p. 200) afirma que a "realidade do gênero é a realidade social de sua realização no processo de comunicação social", funcionando como um "conjunto de meios de orientação coletiva na realidade". Essa orientação faz com que os sujeitos compreendam novos aspectos da realidade que os rodeia. Essa orientação social do gênero se estabelece em via de mão dupla, conforme pontua Medviédev ([1928]2012). O autor esclarece que os gêneros orientam-se, tanto para os interlocutores quanto para a vida, "por meio do seu conteúdo temático". É possível entender que os gêneros discursivos orientam-se sempre em relação dialógica com os acontecimentos dos sujeitos em sociedade e o seu conteúdo temático deixa entrever muitas dessas 
relações (MEDVIÉDEV, [1928]2012, p. 195).

Tendo em vista essa orientação nas esferas sociais de comunicação, os gêneros do discurso constituem-se de três elementos dinâmicos: forma composicional, estilo e conteúdo temático, isto é, os gêneros possuem uma estrutura recorrente, que tem relativa estabilidade em função da individualização que o locutor lhe atribui a cada nova interação verbal. Por ser ligado intrinsecamente à vida e às atividades sociais dos mais diversos tipos, o estilo torna-se parte fundamental nesses processos de relativa estabilidade do gênero e orientação para a realidade social.

É importante destacar que, quando discutem acerca da forma composicional, os estudos bakhtinianos não estão propondo uma fôrma na qual se fazem caber os discursos. A forma composicional de um gênero está ligada a uma forma arquitetônica que dá contornos específicos aos enunciados. Essa arquitetônica envolve, segundo Brait e Pistori (2012, p. 378), o estudo do texto "por suas condições concretas de vida, suas interdependências, suas relações, suas posições dialógicas e valorativas". Ademais, isso implica entender o estudo dos gêneros do discurso em sua totalidade, observando sua relação intrínseca com o meio social mais imediato e o mais amplo. Com efeito, compreendemos que os gêneros precisam ser estudados na esteira de suas tradições socioverbais, a fim de que se entendam as relações dialógicas que estabelecem com os outros discursos que lhes precedem e que lhes sucedem.

Assim, os gêneros do discurso, no escopo das concepções propostas pelo Círculo, são colocados como meios de compreensão e interação com a realidade, que se organizam como temas nas diferentes esferas da comunicação. A unidade temática de um gênero não pode ser confundida com o assunto, mas precisa ser vista como um elemento que faz parte desse tecido social do qual emerge o gênero. Conforme Medviédev ([1928]2012),

[...] o tema transcende sempre a língua. Mais do que isso, o tema não está direcionado para a palavra, tomada de forma isolada, nem para a frase e nem para o período, mas para o todo do enunciado como apresentação discursiva. O que domina o tema é justamente esse todo e suas formas, irredutíveis a quaisquer formas linguísticas. O tema de uma obra é o tema do todo do enunciado, considerado como determinado ato sócio-histórico. Por conseguinte, o tema é inseparável tanto do todo da situação do enunciado quanto dos elementos linguísticos (MEDVIÉDEV, [1928]2012, p. 196).

Analisando esse trecho, podemos perceber que o tema de um gênero sempre tem origem a partir da vida, das situações sociais nas quais os sujeitos interagem socialmente. Por isso, um tema sempre está ligado a outros temas, sendo inseparável desse elo dialógico no qual surge e também dos aspectos temporal e espacial imbricados nesse processo. Por fim, compreendemos o tema para além da sua dimensão linguística, conforme postula Medviédev no trecho citado. O tema 
materializa-se nos elementos semânticos da língua e é, portanto, inseparável da dimensão semântica e da dimensão ideológica dos temas sociais que se originam nas esferas da atividade humana.

Nessa perspectiva, o estilo, outra característica que constitui o gênero, também participa desse processo dialógico de movimentação discursiva de temas que orientam o tecido social. O locutor, ao mobilizar determinado gênero, atualiza e ressignifica tanto a forma composicional, dependendo do gênero, quanto a unidade temática com sua posição axiológica. Faraco (2009, p. 137) explica que o Círculo de Bakhtin, em diversas obras, refere-se ao estilo do locutor como um elemento que se constrói a partir de um julgamento social de valor, isto é, “[...] as seleções e escolhas são primordialmente tomadas de posição axiológicas frente à realidade linguística", considerando uma gama de vozes sociais que avaliam um mesmo objeto.

Percebemos, desse modo, a relação sempre tensa do que é dado (forma com relativa estabilidade do gênero) com $o$ novo (ressignificação axiológica do estilo do locutor), postulado pelas reflexões bakhtinianas. Por isso, discutir a noção de gênero é bastante complexo, já que, de um lado, há o uso da língua, que é individual, mas sempre em relação de alteridade, e, de outro, os enunciados, que seguem uma repetibilidade própria de cada gênero, que é ao mesmo tempo dinâmica.

Sobral explica que:
[...] o gênero discursivo é estável porque conserva traços que o identificam como tal e é mutável porque está em constante transformação, se altera a cada vez que é empregado (2009, p. 115).

Com efeito, não se tratam de "estruturas fixas de enunciados nem de enunciados-tipo". Concordamos com o autor quando argumenta que isso reduziria o gênero, entidade viva e complexa, ao plano linguístico estrito.

Ao considerarmos, então, o enunciado sempre em relação aos julgamentos sociais de valor, compreendemos que o enunciado concreto e vivo está impregnado de diversas entonações que mantêm entre si relações de tensão, de encontro dialógico. Por meio dessa tensão, podemos vislumbrar a própria natureza do enunciado que vive em um contínuo elo da comunicação social. Para Bakhtin (2003, p. 297), os enunciados não são "indiferentes entre si nem se bastam cada um a si mesmos", ou seja, os enunciados não vivem isoladamente na comunicação, uma vez que os seus sentidos dependem dos ecos e das ressonâncias de outros já ditos, os quais estão ligados "pela identidade da esfera de comunicação discursiva".

Segundo Bakhtin (2003, p. 262), os gêneros discursivos são "tipos relativamente estáveis de enunciados", que se engendram em diversas esferas da atividade humana na sociedade. Se, como dissemos anteriormente, uma esfera discursiva não é um espaço físico propriamente dito, ela, então, traduz uma atmosfera social de atividade, podendo se engendrar em 
diferentes contextos de interação verbal. Podemos destacar diversas esferas, tais como esfera acadêmica, jurídica, política, midiática, religiosa, literária, entre outras. Salientamos, no entanto, que as esferas são dinâmicas, podendo encontrar-se umas com as outras, em determinado contexto de comunicação. É o caso, por exemplo, do nosso objeto de estudo, o culto televisivo Show da fé, que se encontra no limiar de pelo menos duas esferas discursivas: a esfera religiosa e a esfera midiática.

Em Marxismo e filosofia da linguagem, é oferecida uma orientação de análise que pretende abranger o percurso da interação verbal sem desconsiderar cada elemento do processo complexo da comunicação. Como os signos ideológicos materializam-se na movimentação das diversas esferas sociais, eles constantemente se veem marcados pelo "horizonte social de uma época e de um grupo social determinado" (BAKHTIN/ VOLOCHINOV, [1929]2010, p. 45). Por isso, a primeira consideração metodológica é não dissociar a materialidade do signo da sua ideologia, localizando-o no campo discursivo em que o signo aparece enunciado. A segunda orientação é não observar o signo fora das "formas concretas da comunicação social”, ou seja, deve-se analisar o signo no contexto concreto do gênero discursivo mobilizado, uma vez que o signo ideológico não tem sentido fora desse sistema comunicacional. $\mathrm{Na}$ terceira e última proposta metodológica de análise, o pensador russo orienta $o$ pesquisador a não desprender o signo e a comunicação de sua base material, ou seja, a materialidade linguística do enunciado (BAKHTIN/VOLOCHINOV, [1929]2010, p. 45).

Ao considerar os enunciados sempre situados em um campo discursivo, os filósofos da linguagem abrem espaço para pensarmos nas relações dialógicas entre diferentes discursos em determinado campo da atividade humana, considerando a complexidade das ações envolvidas. Em Questões de literatura e de estética, Bakhtin também aborda o gênero romanesco como pano de fundo de suas discussões em torno do plurilinguismo. ${ }^{2}$ Bakhtin ([1975]2010b) chama de plurilinguismo dialogizado o efeito de sentidos decorrente do encontro de diferentes vozes, discursos e linguagens sociais que ressoam no enunciado. Tais vozes articulam-se formando uma espécie de andaime que sustenta o discurso, tendo em vista o momento social e histórico da enunciação. Aliás, segundo o viés bakhtiniano, é importante frisar a importância social que a linguagem desempenha, criando no locutor a capacidade de configurar-se em uma cultura, em uma ideologia (BAKHTIN, [1975]2010b, p. 133).

É interessante ressaltar que o conceito de polifonia é pouco produtivo no que tange à análise de discursos das esferas cotidianas, tornando-se mais adequada a aplicação do conceito de plurilinguismo para tratar do encontro de diferentes vozes nos discursos cotidianos. Na visão do Círculo de Bakhtin, a linguagem estaria 
sempre ligada à estratificação socioaxiológica, não sendo possível tratar de diferentes vozes sem considerar essa hierarquização de valores sociais no discurso (FARACO, 2009, p. 71). A estratificação social é no sentido de que, na sociedade, os discursos convivem e divergem por conta das diferentes posições de poder e de hierarquias que ocupam nas esferas da atividade humana. Podemos citar, como exemplo, o embate de vozes conflitantes e com diferentes posições axiológicas dentro de esferas bastante conhecidas, tais como a esfera política, a acadêmica, a religiosa, a jurídica, entre outras. Em todas essas esferas, observamos o diálogo de distintas vozes e valores que não caminham harmoniosamente, pelo contrário, elas lutam, combatem e sobrepõem-se hierarquicamente umas às outras.

Ao pressupor essa estratificação, entendemos que os discursos que circulam na sociedade, inevitavelmente, têm poderes sociais, políticos e econômicos diferenciados, e por isso essas vozes não poderiam dialogar em pé de igualdade, em polifonia, conforme postulou Bakhtin a partir dos textos de Dostoiévski. Assim, é possível considerar que, quando traz discussões concernentes ao plurilinguismo no romance, Bakhtin ([1975]2010) está realizando seu projeto de mostrar que a linguagem nasce e se desenvolve a partir de uma complexidade dialógica no terreno da diversidade de vozes, dos gêneros discursivos, das palavras alheias introduzidas nas nossas, dos discursos autoritários que convivem com discursos subversivos. Enfim, o filósofo russo quer nos mostrar que essa complexidade dialógica constitui a natureza da linguagem, constituindo também o sujeito e a sociedade que o engendra.

Diante dessas questões que envolvem o princípio dialógico da linguagem, podemos afirmar que a realidade da língua é esse encontro ininterrupto de vozes sociais, já ditos e valores que perpassam a história e a cultura de uma sociedade. A natureza dialógica da linguagem estende-se para os sujeitos e para a vida. Nascemos em uma sociedade marcada por diferentes posicionamentos valorativos e elaboramos nossos posicionamentos, nossos discursos, enfim, nossa vida sempre em direção ao diálogo tenso com a palavra ativa e responsiva do outro.

Destacamos, ao final desta seção, a complexidade envolvida no encontro das esferas midiática e religiosa, frisando também o desafio de analisar esse encontro, do ponto de vista teórico e metodológico, considerando as diferentes áreas do conhecimento que arquitetam a discussão. Na próxima seção, procuramos mostrar essa complexidade, a fim de compreendermos o entrelaçamento das esferas em jogo e debatermos nossas relações sociais e políticas com a religião, na contemporaneidade.

\section{Mídia e religião: esferas discursivas (e)m tensão}

As esferas midiática e religiosa, sobretudo das religiões neopentecostais, configuram-se como espaços dinâmicos (tensos) de acirrada concorrência entre 
vários discursos religiosos que disputam a atenção/adesão do fiel e de sua eventual contribuição em dinheiro. Por ser a mídia uma esfera de difusão, sua junção à esfera religiosa contribui para duas tarefas básicas das religiões neopentecostais: evangelizar e aumentar seu conglomerado pelo mundo afora. Conforme Charaudeau (2010, p. 19), a mídia encontra-se na "contingência de dirigir-se a um grande número de pessoas, ao maior número, a um número planetário, se possível”. O autor sublinha que, para despertar o interesse e tocar a afetividade do destinatário, a quem se dirige a informação (o conteúdo que é veiculado pela mídia de maneira geral), a mídia distribui as informações de forma a atingir o maior número de pessoas, simplificando conceitos, criando clichês e estereótipos (CHARAUDEAU, 2010, p. 19-20).

Convém ressaltar que o autor francês faz essas considerações tendo como foco o discurso da informação, ou seja, discursos da esfera jornalística. No entanto, podemos ampliar essas reflexões para além desses gêneros e pensar a respeito da relação da mídia com outras esferas, como a religiosa, que é o caso do Show da fé, mostrando, dessa forma, a amplitude de tal esfera. De acordo com Charaudeau (2010, p. 19-20), a mídia impõe, de certa forma, o que se constrói do espaço público, uma vez que é a linguagem a mediação necessária no processo de "transmissão". O autor salienta que "a linguagem não é transparente ao mun- do, ela apresenta sua própria opacidade através da qual se constrói uma visão, um sentido particular do mundo".

Assim, no momento em que a mídia seleciona o que será difundido, constrói-se "uma imagem fragmentada do espaço público, uma visão adequada aos objetivos das mídias". Entendemos que tal fragmentação é adequada, pois, se a mídia tem o objetivo de atingir o maior público possível, é vantagem que apareçam diversificados reflexos da realidade social, de maneira a atingir as diversas opiniões, os valores, as crenças, etc. Conclui Charaudeau (2010, p. 20), nessa perspectiva, que a mídia é um "espelho deformante", que mostra a realidade de um mundo deformado, ou seja, fragmentos amplificados, simplificados e/ou estereotipados desse mundo.

As imagens fragmentadas da realidade apresentam-se na mídia sob duas lógicas, segundo Charaudeau (2010, p. 21): a "lógica econômica" e a "lógica simbólica". A primeira lógica faz com que "todo organismo de informação aja como uma empresa, tendo por finalidade fabricar um produto que se define pelo lugar que ocupa no mercado de bens e consumo"; já a segunda lógica faz com que "todo o organismo de informação tenha por vocação participar da construção da opinião pública". Embora o autor esteja tratando de discursos da informação, podemos compreender também que as esferas religiosa e publicitária, por exemplo, trabalham, basicamente, operando essas lógicas de maneira di- 
nâmica: de um lado, há a construção e a propagação de produtos religiosos, no caso de um culto televisivo, postos ao consumo, e, de outro, notamos as nuances da construção e propagação de ideias, valores, opiniões, estereótipos, que, de certa forma, também estão à venda na prateleira, junto aos produtos.

Associando-se essas lógicas à mídia televisiva, podemos compreender a dimensão publicitária que envolve os diferentes discursos religiosos televisivos. A televisão por si só apresenta-se como uma empresa, um empreendimento que faz a regulação entre o seu próprio sustento (os patrocínios, a publicidade, a indústria que gira em torno da televisão) e os discursos e valores veiculados por ela (as programações). No caso dos programas religiosos, principalmente os cultos neopentecostais, os que mais ocupam espaços em horários de acirrada concorrência, percebemos a televisão atuando como facilitadora das religiões, tendo em vista essas duas lógicas.

A televisão, com efeito, abre espaços bastante caros e veicula programações religiosas e seus patrocinadores: a igreja lucra com sua ampla e massiva divulgação e faz lucrar também a indústria da televisão (lógica econômica). Com o lucro garantido e o espaço de concorrência aberto, a doutrina religiosa neopentecostal e seus valores simbólicos atingem uma grande parte da população e têm consequências profundas no contexto social brasileiro, como na política, por exemplo, em que temos uma bancada evangélica de 78 parlamentares ${ }^{3}$ (lógica simbólica).
A televisão, no contexto dessa esfera, é um dos meios que mais atingem a maioria da população, em suas diversas camadas socioeconômicas. Ao se constituir no domínio do visual e do sonoro, a televisão, conforme nos explica Charaudeau (2010), mostra ao público o seu produto baseado na combinação de dois sistemas semiológicos: o da imagem e o da palavra. Segundo o autor francês, por meio dessa combinação, emerge um produto muito eficaz em fabricar imaginário para 0 grande público. Nessa ótica, a TV funcionaria como um "espelho", que mostra, exibe e, enfim, "devolve ao público aquilo que é sua própria busca de descoberta do mundo" (CHARAUDEAU, 2010, p. 223).

Apresentando-se como um espelho que reflete as aspirações de seu interlocutor, a televisão articula entre si três espaços de construção de sentidos. De acordo com Charaudeau (2010), a televisão tem:

[...] um espaço externo, onde surgem os acontecimentos do espaço público, um espaço interno, onde se desenrola a cena midiática de representação dessa realidade, e um espaço interno-externo, que seria o lugar em que se articula uma relação simbólica de contato entre instância midiática e instância telespectadora (CHARAUDEAU, 2010, p. 223).

Desse modo, compreendemos que os discursos veiculados na televisão são reflexos e refrações da realidade, uma vez que a mídia televisiva realiza, por um lado, um movimento de voltar-se ao mundo externo (social) e lançar a essa realidade um olhar axiológico, valorativo. Por outro, a mídia televisiva reelabora discur- 
sivamente essa realidade social, criando possibilidades de sentidos e dialogando com outras visões sobre a mesma realidade. Nessa dupla orientação de olhar o fato e relatá-lo, recriá-lo, ressignificá-lo, a TV cria laços, vínculos ideológicos, culturais (e econômicos) com seu telespectador, passando a integrar sua vida cotidiana.

Na visão de Dufour (2005, p. 121), a televisão ocupa um lugar preponderante no espaço familiar, constituindo um "verdadeiro adestramento precoce para o consumo e uma exortação à monocultura da mercadoria”. Tais investidas, obviamente, são carregadas de intenções ideológicas (DUFOUR, 2005 p. 121). Não seria diferente nas investidas do discurso religioso que promete a vida perfeita e a felicidade plena a vários tipos de preços. Assim, se, em uma ponta, há o pastor e a liderança da igreja, mobilizando a palavra divina com as devidas seleções discursivas e valorativas, na outra, há o interlocutor que está totalmente disponível a receber essa palavra e as investidas ideológicas que com ela se apresentam. O outro, isto é, o telespectador do culto televisivo ou o fiel participante da igreja é um sujeito extasiado diante da apoteose de promessas de milagres que pode conseguir por intermédio da fé.

A tríade "fiel-televisão-culto" é baseada em relações de consumo que ultrapassam as barreiras da dimensão religiosa (simbólica). Consome-se a fé, a doutrina, a possibilidade de milagres e produtos que levam à fé e inserem o sujeito-crente no jogo religioso-mercadológico. Lipovetsky (2014a) discute acerca do consumo e suas transformações ao longo da história da sociedade, levando-nos a pensar na problemática que inclui questões religiosas nesse contexto capitalista. De acordo com o autor francês, o capitalismo do consumo pode ser dividido em três fases, que, certamente, não são estanques, mas se complementam no desenrolar das transformações econômicas da sociedade.

A primeira fase observada por Lipovetsky (2014a) foi marcada pelo nascimento dos mercados de massa, por volta dos anos 80 do século XIX, e finalizada com a Segunda Guerra Mundial. Nessa fase, ampliou-se a infraestrutura dos modos de produção, transporte e comunicação, iniciando uma etapa de democratização das compras de bens duráveis. A segunda fase do capitalismo do consumo é dominada pela lógica da abundância e desenvolve-se, amplamente, o modelo tayloriano-fordiano ${ }^{4}$ de organização da produção. Nessa fase, aumenta-se o poder de compra discriminatório, difunde-se $o$ crédito e as massas passam a ter acesso a uma procura material psicologizada e individualizada, passando a aspirar a um modo de vida até então exclusivo das elites (LIPOVETSKY, 2014a, p. 34-35).

Já a terceira fase é denominada pelo autor como a fase do hiperconsumo. Entendemos que o filósofo coloca o prefixo "hiper" para tratar de um fenômeno relativo ao consumo que se refere à temporalidade: na contemporaneidade, consome-se, livremente, ultrapassando-se as barreiras do espaço, do tempo, 
das classes e, enfim, das esferas. Nessa fase, a comercialização das necessidades é engendrada por uma lógica desinstitucionalizada, subjetiva, emocional. É a fase da busca do bem-estar no mundo (LIPOVETSKY, 2014a, p. 35-36).

Segundo Dufour (2005, p. 118), o novo capitalismo, o qual associamos claramente à terceira fase do capitalismo de consumo, defendido por Lipovetsky (2014a), reforça sua dominação social e cultural não mais por meio de "repressões institucionais", mas a solidificação desse novo capitalismo neoliberal impôs uma "maneira muito menos constrangedora e menos onerosa de garantir sua sorte" (DUFOUR, 2005, p. 118), ou seja, quebrando as instituições que proclamavam valores morais, essa nova forma de economia garante a abertura total das fronteiras do Mercado. Com isso, o sujeito pós-moderno, imerso em um mar de valores puramente monetários, torna-se:

[...] um sujeito disponível para todas as conexões, um sujeito incerto, indefinidamente aberto aos fluxos de mercado e comunicacionais, em carência permanente de mercadorias para consumir. Um sujeito precário em suma, cuja precariedade mesma é exposta à venda no Mercado, que pode aí encontrar novos escoadouros, tornando-se grande provedor de kits identitários e de imagens de identificação (DUFOUR, 2005, p. 118).

Nessa perspectiva, podemos afirmar que a esfera midiática é um dos meios mais eficazes de propagação de ideias, valores e pontos de vista. O neoliberalismo encontra, então, nessa esfera discursiva e na televisão, o terreno ideal para se dirigir a esse sujeito aberto ao consumo. A liderança religiosa, dessa forma, atingindo o fiel e tendo sua adesão ao discurso proferido, tem também sua contribuição monetária. Instaura-se uma verdadeira relação de troca com Deus, mediada pelo discurso da igreja que promete veemente a lógica: se sou associado mensal do programa (culto televisivo), se contribuo com ofertas e se pago o dízimo, serei automaticamente abençoado, recompensado por esse "deus" mercadológico. Nesse sentido, os sujeitos são facilmente atingidos pela televisão e pelo culto neopentecostal espetacularizado nela veiculado, tanto que depositam dinheiro na conta da igreja, a fim de, explícita ou implicitamente, obter as diversas benesses divinas.

Essa relação, quase que de "compra da benesse", é permitida em um novo espaço de consumo, denominado por Lipovetsky (2014a) de consumo contínuo. Essa nova forma de consumir é dessincronizada, contínua, hiperindividualista. Segundo Lipovetsky (2014a, p. 10), “[...] o espírito do consumo conseguiu infiltrar-se até na relação com a família e a religião, a política e o sindicalismo, a cultura e o tempo disponível". Consome-se pela busca de um bem-estar no mundo, de um conforto psíquico, por isso é cada vez mais crescente a "expansão do mercado da alma" e dos "manuais que prometem a felicidade e a sabedoria" (LIPOVETSKY, 2014a, p. 11).

Assim, a fase do hiperconsumo é marcada pela dilatação da organização temporal do consumo. Segundo Lipovetsky 
(2014a, p. 93), essa dilatação temporal alarga "progressivamente os tempos (vazios) ou (protegidos), colocando os dias feriados e a vida noturna à mercê do mercado". Não obstante, é possível perceber, em nossas cidades e na esfera midiática, a abertura contínua de espaços de consumo, como shoppings, bares, supermercados, farmácias 24 horas, etc. Nesse contexto, enquadram-se as igrejas também. Tanto nas cidades, quanto na mídia, percebemos seu modo contínuo de funcionar e atender às necessidades psicológicas e materiais de seu público-alvo.

A procura pelos templos físicos e midiáticos é permeada de uma busca tipicamente característica da contemporaneidade, qual seja, a satisfação imediata de demandas de diferentes setores da vida que proporcionam um bem-estar, uma satisfação, uma sensação de acomodação ao mundo. Desse modo, estamos diante de um consumo que deixou de ser, nas palavras de Lipovetsky (2009, p. 201), "uma lógica do tributo estatutário, passando para a ordem do utilitarismo e do privatismo individualista". É por isso que, por meio dos objetos e das marcas, e, no nosso caso, das doutrinas religiosas neopentecostais, consome-se poder, elegância, modos de ser, segurança, felicidade e outras tantas imagens que influem em nossas escolhas e em nossos comportamentos sociais (LIPOVETSKY, 2009, p. 203).

A religiosidade, na era do hiperconsumo, circunscreve-se no consumo-Providência ${ }^{5}$ ou seja, no consumo da felicidade e da resolução de demandas por vias divinas de operacionalização. Conforme Lipovetsky (2014a), a Igreja, de um modo geral, deslocou sua ênfase nas noções de pecado mortal, de renúncia e sacrifício para a ênfase na ideia de prazer, de felicidade terrena. Houve, segundo o filósofo francês, "uma reinterpretação global do cristianismo", ajustando-se à doutrina os ideais de felicidade e hedonismo difundidos pelo capitalismo de consumo. Efetivamente, “[...] o efeito hiperbólico do consumo não foi a sepultura da religião, mas o instrumento da sua adaptação à civilização moderna da felicidade terrena" (LIPOVETSKY, 2014a, p. 112).

De forma espetacular e fragmentando as fronteiras do tempo e do espaço com o auxílio das mídias, Lipovetsky (2014a, p. 112) chama a atenção para o fato de que a "espiritualidade tornou-se mercado das massas, produto a comercializar, setor a gerir e a promover". Assim, as mídias e seu leque de possibilidades de consumo religioso alavancam a concorrência, o que acaba formando um "cardápio" religioso que se engendra em diferentes esferas sociais. É o espetáculo das possibilidades, da barganha, das promessas do consumo-Providência em horário nobre na televisão e em um continuum temporal na mídia em geral, como na internet, por exemplo.

Sobre essa questão, é importante discutir a respeito das esferas em foco, alguns aspectos referentes à sociedade do espetáculo, conforme é discutido por 
Debord (2003). O autor explica que o espetáculo é a forma contemporânea de organização capitalista de sociedade, sendo uma relação mediatizada por imagens. Conforme o autor, o espetáculo é "o coração da irrealidade da sociedade real". Sob todas as suas formas particulares de publicidade e de informação, o espetáculo "constitui o modelo presente da vida socialmente dominante", sendo a "afirmação onipresente da escolha já feita na produção, e no seu corolário o consumo". Baseando as negociações da sociedade do consumo, o espetáculo apresenta-se como algo "grandioso, positivo, indiscutível” (DEBORD, 2003, p. 15). Podemos entender que as espetacularizações na mídia, por exemplo, mostram a grandiosidade de uma realidade construída, incitam os sujeitos, em sua alienação, a entrar no jogo da concorrência, isto é, nas relações econômicas e simbólicas que envolvem o consumo.

Nesse sentido, Debord (2003, p. 14) explica que "[...] o espetáculo não é um conjunto de imagens, mas uma relação social entre pessoas mediatizadas por imagens". É por isso que a "linguagem do espetáculo é constituída por signos da produção reinante, que são ao mesmo tempo o princípio e a finalidade última da produção" (DEBORD, 2003, p. 15). O espetáculo, no sentido mais amplo do termo e associando-se a esse conjunto de imagens, refere-se a um espectro de valores postos em evidência, suscitando espectadores, sujeitos dispostos a entrar no jogo de entretenimento e da busca de sensações. A sociedade do espetáculo cria, nos diversos dispositivos de comunicação, mecanismos de prender a atenção dos sujeitos, levando-os a experimentar tensamente o consumo de sensações que englobam a coletividade e a individualidade.

No contexto das religiões evangélicas neopentecostais, nicho do qual faz parte o Show da fé, o consumo subjetivo e emocional de que trata Lipovetsky (2014a) ganha contornos espetaculares através dos signos ideológicos verbais e não verbais engendrados nas duas esferas em jogo: a midiática televisiva e a religiosa (esfera de origem desse discurso).

Os signos, de maneira dialógica e em um espectro de valores sociais, suscitam ideias de prosperidade e Providência divina. Um exemplo pode ilustrar a problemática dos signos no espetáculo neopentecostal nas esferas em estudo. Os nomes das instituições religiosas por si só demonstram a que universo de valores estão filiados seus dirigentes. Destacamos os nomes de três igrejas que fazem reverberar a ideia de alcance máximo e promessa de Providência: a Igreja Universal do Reino de Deus (IURD), liderada por Edir Macedo, a Igreja Internacional da Graça de Deus (IIGD), liderada por R. R. Soares, e a recente no cenário brasileiro Igreja Mundial do Poder de Deus (IMPD), liderada por Valdemiro Santiago.

Os signos ideológicos referentes aos nomes das igrejas, reunidos nas esferas em jogo, fazem emergir a atmosfera de 
valores de consumo-Providência, por meio dos signos "Reino de Deus", "Graça de Deus" e "Poder de Deus", integrando um cenário de ampla abrangência, de superação de fronteiras geográficas, por meio dos signos "Universal", "Internacional" e "Mundial". É um contexto de duplo sucesso espetacularizado no próprio nome da instituição, ou seja, é o sucesso da igreja que se expande por todo o mundo, atingindo um grande número de pessoas, e é o sucesso prometido a quem frequenta e a quem consome a doutrina, beneficiando-se do poder, da graça e do reino de Deus (signos referentes a benesses).

Ribeiro (2015) destaca que tais instituições e suas evidentes ambições de arrebanhar adeptos ao seu universo de consumo, ao longo dos anos, sedimentaram seus discursos para além dos templos, ganhando a mídia radiofônica e a televisiva como aliadas ao espetáculo que envolve fé e milagres. Assim, a relação das igrejas denominadas pentecostais e neopentecostais com a esfera midiática e com a disputa acirrada na televisão não é recente.

De acordo com Campos (2004, p. 148), “[...] a história dos evangélicos está ligada, desde o seu início no século XVI, mais que a dos católicos romanos, às novas tecnologias de comunicação social". Desde a década de 1950, as igrejas pentecostais vêm se expandindo em programas de rádios em todo o Brasil. $\mathrm{Na}$ televisão brasileira, os programas evangélicos começam a surgir na década de 1960, em emissoras como a TV Tupi, TV Record, Bandeirantes, entre outras. Segundo Moraes (2010, p. 45), o primeiro programa evangélico na TV brasileira foi ao ar "no dia 18 de novembro de 1962, intitulado Fé para Hoje, apresentado pelo pastor Alcides Campolongo e sua esposa".

Desde essa data, muitos outros programas surgiram na TV brasileira e o mercado religioso-midiático tornou-se cenário de compra dos melhores horários na televisão. Embora algumas denominações pentecostais tenham conquistado espaço em muitos horários, em emissoras brasileiras, ao longo dos anos, diversas igrejas iniciaram sua pretensão de obter uma emissora própria, ampliando, desse modo, seu controle e sua visibilidade na mídia televisiva. Em 1989, a Igreja Universal do Reino de Deus, por exemplo, adquire a Rede Record de Televisão; em 1999, a Igreja Internacional da Graça de Deus aumenta seu conglomerado midiático, adquirindo a concessão da Rede Internacional de Televisão, a RIT. É importante destacar, nesse contexto de concorrência, que o projeto da RIT oferece ao público em geral uma programação de conteúdo quase exclusivamente evangélico, diferindo da proposta da Record. Diferentemente de uma emissora comum, a RIT conta unicamente com uma publicidade voltada a produtos e serviços evangélicos, dirigindo-se a um público heterogêneo, não necessariamente fiéis frequentadores da Igreja da Graça (MORAES, 2010, p. 145). 
É necessário observar o embate de vozes que se travou, ao longo de muitos anos, desde a entrada das pentecostais na mídia. A presença pentecostal marcante na mídia tem causado disputas e rivalidades tanto aos concorrentes da própria esfera religiosa, quanto aos concorrentes de outras esferas. Podemos citar como exemplo veículos de comunicação que mantêm essa rivalidade em relação aos evangélicos: a Rede Globo, o SBT, a Folha de S. Paulo, entre tantos outros que têm uma grande presença no controle da mídia no país.

Com uma ampla visibilidade nas mídias radiofônica e televisiva, os grupos religiosos pentecostais e neopentecostais ganham espaço também na esfera política. Mariano e Pierucci (1992, p. 93) explicam que o marco histórico da imersão pentecostal na esfera política "foi surpresa geral”, com "a eleição de uma bancada de 33 parlamentares evangélicos para o Congresso Nacional Constituinte, em 1986". De acordo com Pierucci (1989), as denominações evangélicas formam parte da base social de uma "nova direita", pois adicionam valores tradicionalistas referentes à família, à sexualidade e às pilastras usualmente associadas a posições "direitistas", tais como a defesa do direito de propriedade, a resistência em relação à reforma agrária e à ampliação da intervenção do Estado na economia.

Desse modo, podemos assinalar que o movimento pentecostal ${ }^{6}$ chegou ao Brasil trazendo novas delineações em diversas esferas da sociedade. Mariano (1996, p.
25) destaca que o pentecostalismo chegou ao Brasil importado da cultura pentecostal norte-americana, há mais ou menos cem anos, e "desde então centenas de igrejas se formaram e diversas mudanças ocorreram em seu interior, tornando esta religião cada vez mais complexa, heterogênea". Recentemente, diversos pesquisadores da área da sociologia da religião passaram a organizar essa esfera religiosa em três perspectivas, que não são estanques, mas convivem e se influenciam mutuamente.

Mariano (1996, p. 25) afirma que a primeira perspectiva é chamada de “pentecostalismo clássico" e abrange o "período de 1910 a 1950, que vai de sua implantação no país, com a fundação da Congregação Cristã no Brasil (em 1910, em São Paulo) e da Assembleia de Deus (1911, Pará)". O autor acentua que: "desde o início estas igrejas caracterizaram-se pelo anticatolicismo, pela ênfase no dom de línguas, por radical sectarismo e ascetismo de rejeição do mundo". A segunda perspectiva é denominada "pentecostalismo neoclássico" e teve "início na década de 50 com a chegada em São Paulo de dois missionários norte-americanos da International Church of The Foursquare Gospel". É nesse período, também, que os missionários emancipam-se das organizações estrangeiras e criam suas próprias organizações no Brasil. Cria-se, nessa fase, a Cruzada Nacional de Evangelização, com base na cura divina, e funda-se, em São Paulo, em 1951, a Igreja do Evangelho 
Quadrangular (IEQ), que, diferente das demais, é predominantemente liderada por mulheres, e, ainda, as Igrejas Brasil Para Cristo (1955, São Paulo), Deus É Amor (1962, São Paulo), Casa da Benção (1964, Minas Gerais), e outras de menor porte (MARIANO, 1996, p. 125).

A terceira perspectiva é denominada "neopentecostal", sendo a vertente que mais cresceu nas últimas décadas. Conforme Mariano (1996), o neopentecostalismo começou na segunda metade dos anos 1970, crescendo e fortalecendo-se na esfera religiosa (evangélica) no decorrer dos anos 1980 e 1990. Mariano (1996, p. 26) observa que as igrejas que seguem a linha neopentecostal apresentam "forte tendência de acomodação ao mundo", participando ativamente da política partidária do país e utilizando "intensamente a mídia eletrônica". De acordo com o sociólogo da religião, o neopentecostalismo caracteriza-se por três principais aspectos, que constituem as bases das pregações das igrejas que seguem essa linha. $\mathrm{O}$ primeiro aspecto refere-se à ênfase dada à guerra espiritual contra o Diabo e seus anjos decaídos, chamados, muitas vezes, de demônios e associados às outras religiões, sobretudo aos cultos afro-brasileiros (MARIANO, 1996, p. 26).

$\mathrm{O}$ segundo aspecto, ainda conforme nos explica Mariano (1996), refere-se à não adoção dos "tradicionais e estereotipados usos e costumes de santidade, que até há pouco figuravam como símbolos de conversão e pertencimento ao pentecos- talismo". É importante destacar, nesse sentido, que os adeptos do neopentecostalismo abandonam os modos de vestir, por exemplo, apregoados pelas igrejas pentecostais tradicionais, nas quais as mulheres são orientadas a usar vestidos longos ou saias, para que se distingam dos homens, que usam calças compridas.

Por fim, o terceiro aspecto, no qual nos deteremos mais detalhadamente, refere-se à pregação e à difusão da Teologia da Prosperidade, defensora do polêmico e mal interpretado axioma franciscano ${ }^{7}$

[...] "é dando que se recebe" e da crença nada franciscana de que o cristão está destinado a ser próspero materialmente, saudável, feliz e vitorioso em todos os seus empreendimentos terrenos (MARIANO, 1996, p. 26).

As principais igrejas que compõem o cenário neopentecostal brasileiro são as seguintes: Universal do Reino de Deus (1977, Rio de Janeiro), Internacional da Graça de Deus (1980, Rio de Janeiro), Comunidade Evangélica Sara Nossa Terra (1976, Goiás) e Renascer em Cristo (1986, São Paulo), todas fundadas por pregadores brasileiros. Tais denominações, com a difusão midiática da Teologia da prosperidade, alinham seus discursos em consonância com discursos de promessas da sociedade de consumo, como aqueles de serviços de crédito ao consumidor, de sedutores apelos de lazer, de opções de entretenimento, criadas e exploradas pela indústria cultural (MARIANO, 1996, p. 27).

Assim, Mariano (1996) explica que essa religião se vê compelida a adaptar-se à sociedade do consumo, a fim de 
diminuir sua defasagem em relação à sociedade e aos interesses ideais e materiais dos crentes. Nessa perspectiva, Gomes (2010, p. 15), estudioso das mídias e da religiosidade eletrônica, discute que, na contemporaneidade, "o fenômeno religioso não está enclausurado, mas explode nas mais diferentes práticas e formas midiáticas". Por conta desse fenômeno, "diferentes Confissões Religiosas possuem programas de televisão, montaram redes e impérios televisivos que rivalizam com o campo profano" (GOMES, 2010, p. 15). Entendemos, no entanto, que há, nesse caleidoscópio religioso midiático, uma diferença entre a relação de algumas confissões com a mídia.

Conforme explica Gomes (2010), as neopentecostais, ao contrário da Igreja Católica e das pentecostais mais tradicionais nos usos e costumes, nascem já nesse meio midiático e sua estrutura doutrinal já apresenta, por si mesma, espaço para a acomodação ao meio multifacetado da esfera midiática. $\mathrm{O}$ neopentecostalismo e a teologia da prosperidade encontram na mídia, sobretudo na televisão, e na sociedade do Mercado e do Consumo aliados eficazes de sedução e propagação de suas ideias. A engrenagem mercadológica da pós-modernidade oferece ferramentas econômicas e políticas para que as igrejas e suas pregações, em torno das demandas individuais por saúde e posses materiais, possam interpelar uma grande massa de sujeitos que possa consumir essa crença.
A principal ferramenta é a abertura de espaços públicos e midiáticos a essas instituições religiosas em troca de generosas mensalidades. A busca pela posse de um "poder fazer" está presente nas duas esferas tratadas neste artigo.

$\mathrm{Na}$ esfera midiática, de acordo com Ribeiro (2015), a busca pelo poder concretiza-se no seu patrocínio cada vez maior e na sua amplitude que abarca uma infinidade de outras esferas, isto é, com a injeção econômica e com seus lucros, essa esfera tem, ao mesmo tempo, o poder de girar a roda mercadológica da indústria dos meios de comunicação e o poder de construir, desconstruir, propagar, difundir opiniões, valores sociais, políticos e econômicos para um vasto e incontável público espectador. Na esfera religiosa, a busca pelo poder se traduz em duas dimensões: primeiramente, há a dimensão da própria instituição religiosa, que busca poder atingir o maior número de fiéis contribuintes e fazer, assim, "crescer" sua obra com cada vez mais abertura de templos, programas de rádio, de TV, etc.; em uma segunda dimensão, também há o fiel que é um sujeito participante dessa esfera, aliás, o fiel é a razão de existência de discursos religiosos, o qual busca o "poder fazer" que abarque suas necessidades individuais e sociais. Isto é, o fiel busca, nesses discursos, a benção familiar, sua independência financeira, saúde e curas miraculosas, entre outras demandas.

Cria-se uma nova forma de exercer a religiosidade na contemporaneidade, ou 
seja, a nova Igreja é universal e virtual. Segundo Gomes,

Os templos são os próprios lares; os púlpitos são os aparelhos de televisão; o sinal da pertença ao grupo se expressa no consumo. Somente é fiel dessa Igreja aquele que possui capacidade de consumir alguns produtos por ela vendidos [...]. Em tudo isso, o mais importante é o espetáculo. O culto perde o mistério do sagrado para revestir-se da transparência da mídia, onde a imagem é tudo. Replica-se, nas Igrejas, a lógica da sociedade do espetáculo (GOMES, 2010, p. 31).

Com efeito, entendemos que um grande Mercado envolve as atividades dessa nova Igreja, alavancando sua expansão na sociedade do hiperconsumo. Fausto Neto (2004), pesquisador do campo das mídias e da religião, ressalta que uma grande indústria cultural envolve, atualmente, as religiões de um modo geral. Um grande valor monetário é arrecadado pelos mercados editorial, musical e cinematográfico. Segundo o pesquisador brasileiro, “[...] a internet é também outro indicador dessa indústria cultural, com lojas virtuais oferecendo estruturas de e-commerce para vendas" (FAUSTO NETO, 2004, p. 146). A Igreja Internacional da Graça de Deus, por exemplo, explora um vasto comércio de venda de produtos pelo Shopping do povo de Deus, estabelecimento comercial vinculado à igreja, que oferece produtos tanto na loja virtual $^{8}$ quanto na loja física, situada na Avenida São João, 815, São Paulo.

Fausto Neto (2004) problematiza essa expansão comercial e midiática das religiões neopentecostais no Brasil. A falta de políticas públicas de atendimento da população em suas demandas pode ter dado início à adesão às políticas de atendimento, de salvação, ensejadas pelos discursos neopentecostais. Essas igrejas atuam "em cima do vácuo político-assistencial deixado pelo Estado e outras instituições", criando "estratégias telerreligiosas", que "estruturam os espaços de curas, segundo operações de compra e venda fundamentadas nos alicerces do marketing confessional" (FAUSTO NETO, 2004, p. 147).

As igrejas neopentecostais, nessa perspectiva, emergem no Brasil justamente em um contexto contraditório, de mudanças sociais, políticas e econômicas e de contínuas desigualdades, durante a segunda metade do século XX. O país, nesse período, foi palco de grande expansão e massificação das informações, com mudanças nos padrões de comportamento de consumo. Nos meios de comunicação, a televisão foi o principal veículo que penetrou de forma incomparável uma década em que as redes de telecomunicações atingiram distantes regiões do país. Já no início deste século, o país vive uma grande mudança nos padrões de classes sociais, a partir de um período de baixos índices de desemprego e aumentos significativos de salários. Nesse contexto, as igrejas neopentecostais, estrategicamente, parecem sustentar seus discursos da Teologia da prosperidade de maneira desvinculada desse contexto sociopolítico, atribuindo à dimensão divina os avanços financeiros dos fiéis. 
O discurso da Teologia da prosperidade embaralha as dimensões simbólica e econômica, embaralhando-se também a relação do fiel com a instituição religiosa: ora trata-se de um fiel que participa de rituais, orações, pregações, aprende a doutrina, ora trata-se de um fiel sustentador do empreendimento religioso-televisivo, sendo quem patrocina com dinheiro mensal, quem consome os produtos, quem assina a TV a cabo oferecida. Enfim, a relação entre fiel e Igreja entra no jogo de embaralhamento do discurso da fé e da compra/venda da fé, consumando o que Ribeiro (2015) chama de Mercado da fé.

O Mercado da fé é marcado pelo imperativo do consumo da felicidade e bem-estar, seguindo as reflexões de Lipovetsky (2014a). A felicidade, segundo o autor, é "orquestrada por uma lógica desinstitucionalizada, subjetiva, emocional" (LIPOVETSKY, 2014a, p. 36). A partir de nossas reflexões em torno do encontro de esferas engendrado no Show da fé, podemos compreender que a felicidade propagada pelo show e a almejada pelo fiel são de naturezas diferentes. Busca-se, então, a felicidade emocional da pertença, do engajamento a valores e crenças, da saúde, da harmonia familiar, da saída da miséria extrema, etc. $\mathrm{Na}$ verdade, o Mercado da fé ocupa, cada vez mais, um espaço, tanto físico quanto midiático, de resolução de demandas que o Estado deixou de cumprir ao longo dos anos no Brasil.

\section{$\mathrm{O}$ (in)acabamento do debate: palavras finais}

O arrazoado empreendido neste artigo foi desafiador, no sentido de que foi necessária a incursão em outras áreas do conhecimento, tais como o campo das mídias, a História e a Sociologia da religião, dialogando com os estudos bakhtinianos. Abarcar duas esferas tão complexas é um trabalho que exige reflexões de diferentes áreas, entendendo-se, desse modo, que o estudo da linguagem não pode, isoladamente, dar conta de um campo das ações humanas, ainda mais quando há encontro de campos de ações.

Os estudos da linguagem, principalmente aqueles baseados em uma perspectiva bakhtiniana, fornecem essa possibilidade de intersecção, de intercâmbio entre diferentes áreas do conhecimento, visto que é uma área de estudos que prioriza a linguagem nas relações sociais, culturais e históricas. Por isso, ao se discutir o cenário religioso neopentecostal no Brasil, voltando o olhar para os aspectos discursivos, faz-se necessário buscar reflexões que contornem esse cenário, construindo um ambiente contextual que alimenta esses discursos.

Nessa perspectiva, a noção de esfera da comunicação pode ser compreendida como um "lugar" de certos tipos de coerções que, sem desconsiderar a influência das instâncias sociais, segundo Grillo (2012, p. 143), "constitui as produções ideológicas, segundo a lógica particular de cada campo". No caso da mídia e da 
religião, acontece a fusão de duas lógicas: a religião neopentecostal é irrigada pelo consumo propagado pelos diferentes discursos que circulam na mídia e dela retira os nutrientes necessários para alimentar ideais de felicidade e sucesso, modelos de comportamento, etc.

A religião, por sua vez, encontra na mídia o campo arquitetado pela tecnologia que facilita a evangelização da grande massa. Para isso, a religião passa a lançar mão de características midiáticas e transforma seus cultos em shows, programas de auditórios, interações instantâneas, entre outros recursos. Esses dois campos não se fundem à toa, ao longo da história, visto que tanto mídia quanto religião (principalmente os neopentecostais no Brasil) apresentam discursos propagadores, ou seja, os dois campos visam atingir um grande número de sujeitos por intermédio de dispositivos de difusão.

Por meio da análise das esferas em tensão, entendemos que o discurso da bíblia é transmitido e espetacularizado por seus porta-vozes, recebendo acentuação positiva principalmente a posse de dinheiro e de saúde, benesses esperadas no contexto do consumo-Providência. Nesse discurso, então, emergem diversas imagens de um sujeito aberto a todas as conexões de Mercado. Isso acontece em um complexo meio ideológico, no qual o sujeito está inserido, isto é, o sujeito não está exposto somente ao discurso religioso neopentecostal na televisão, mas, conforme Medviédev (2012, p. 56), esse "homem social está rodeado de fenô- menos ideológicos”, ou seja, está imerso em um espectro de signos ideológicos dos mais variados tipos: está exposto a "afirmações científicas; de símbolos e crenças religiosas; de obras de arte"; de discursos da lei, discursos publicitários infiltrados em outros discursos e assim por diante.

Diante de tais conjecturas, para finalizar, ressaltamos que o debate analítico e crítico, conforme postula Amorim (2002), em torno da interseção entre as esferas midiática e religiosa é inconcluso. É inconcluso tanto no sentido de suas implicações sociais, pois tratamos de ações culturais (a religião é parte de nossa cultura) vivas e reais na cadeia da comunicação dialógica, quanto no sentido de suas implicações linguístico-discursivas, visto que se trata de enunciados em constante modificação, em processo de ressignificação, sendo, portanto, sempre um objeto de estudos em potencial para novas reflexões científicas.

\section{The complexity of interfacing domains of discourse: the case of media and religion today}

\section{Abstract}

This article raises discussions regarding the interface between the domain of media and the domain of religion, observing aspects relative to consumption that constitute neo-Pentecostal religious practices in contemporary society, assuming the dialogic conception of language developed by Bakhtin and his Circle. To this end, primarily, we reflect on the notion of 
discourse domain, based on Bakhtinian studies, also associating the concepts of utterance and discourse genres, in order to substantiate the discussion on how the domains in question here work. Then, we address the domain of media in a dialogic relation to the religious domain, centering the debate on the context of televised neo-Pentecostal discourses. In the analysis of the tension between the two domains, we appeal to different areas of knowledge, in order to explain the complexity involved in the description of the context that involves the neo-Pentecostal discourses in the media.

Keywords: Discourse domain. Media. Religion. Tension.

\section{Notas}

1 Utilizaremos as nomenclaturas "esfera" e "campo" como sinônimas, uma vez que, no conjunto das obras do Círculo, encontramos oscilações desses termos que se referem ao mesmo conceito.

2 Em 2015, o livro Teoria do romance I: a estilística (1930-1936) foi publicado sob a edição russa de Serguei Botcharov e Vadim Kójinov, com tradução, prefácio, notas e glossário de Paulo Bezerra. Na nova versão, o termo plurilinguismo foi traduzido como "heterodiscurso" (BAKHTIN, 2015).

3 Disponível em: <http://zh.clicrbs.com.br/rs/ noticias/noticia/2015/02/bancada-evangelica-ganha-forca-inedita-no-congresso-4704350. html >. Acesso em: 17 jul. 2015.

4 O modelo tayloriano-fordiano é um modelo de organização da produção pautado em princípios que regem grandes empresas. Nesse modelo, há a divisão intensiva das tarefas e a fabricação em grandes séries de produtos estandardizados. Além disso, há intensa repetibilidade mecânica das tarefas, seguindo uma lógica tecnicista, produtivista e quantitativa. O nome do modelo faz menção a Henry Ford e a Frederick Taylor. Ford, no século XX, em Detroit, coloca em prática, na sua fábrica de automóveis, a produção em série através das linhas de montagem. $\mathrm{O}$ sistema implantado por Ford tem base no con- junto de teorias desenvolvido por Taylor, engenheiro norte-americano, que buscava métodos de trabalho que aumentassem a produtividade do trabalho industrial (LIPOVETSKY, 2014b).

5 Expressão utilizada por Ribeiro (2015) para discutir a especificidade do consumo na esfera religiosa neopentecostal, que tem muito de sua base na doutrina da Teologia da prosperidade, na qual o crente tem direito à felicidade terrena, viabilizada por Cristo com sua morte na cruz. Trataremos da Teologia da prosperidade mais adiante, nesta seção.

6 A palavra "pentecostes", do grego pentecostê [heméra], significa quinquagésimo dia depois da Páscoa. Assim, a origem do termo Pentecostalismo remonta à palavra Pentecostal, que vem de Pentecostes, que designa o derramamento do Espírito Santo ("Evidência de novas Línguas"), cinquenta dias após a ressurreição (ascensão de Cristo). Na Bíblia, no Livro de Atos, segundo capítulo, está a narrativa da cena desse evento, ocasião em que os apóstolos se encontravam reunidos em Jerusalém. A semente do Pentecostalismo já estava plantada no protestantismo norte-americano através dos movimentos chamados avivalistas, presentes já no século XVIII, em que acreditavam na promessa do "derramamento do Espírito Santo" (CAMPOS JUNIOR, 1995).

7 O termo "franciscano" remonta à teologia pregada por Francisco de Assis, que tinha como pensamento principal e norteador a pobreza evangélica, na forma mais pura e literal, como verificada nos relatos dos evangelhos, e não somente em relação à pobreza, mas também em relação a ritos litúrgicos durante os cultos. Mesmo respeitando as liturgias, era necessário trazer à existência as palavras dos evangelhos e praticá-las fora do culto, encarnando os mandamentos sagrados na vida diária (TELES, 2006, p. 64).

8 Disponível em: <http://www.spovo.com.br/>. Acesso em: 30 jul. 2015. 


\section{Referências}

AMORIM, M. Abordagem sócio-histórica na pesquisa qualitativa. Cadernos de Pesquisa, São Paulo, n. 116, p. 7-19, jul. 2002.

BAKHTIN, Mikhail (VOLOCHINOV, V. N.). Marxismo e filosofia da linguagem: problemas fundamentais do método sociológico na ciência da linguagem. (1929). Trad. Michel Lahud e Yara Frateschi Vieira. 12. ed. São Paulo: Hucitec, 2010.

BAKHTIN, Mikhail. Estética da criação verbal [1979]. Trad. Paulo Bezerra. 4. ed. São Paulo: Martins Fontes, 2003.

. Para uma filosofia do ato [1920/1924]. Trad. Carlos Alberto Faraco e Valdemir Miotello. São Carlos: Pedro \& João Editores, 2010a.

. Questões de Literatura e de Estética: a teoria do romance [1975]. Trad. Aurora F. Bernardini et al. 4. ed. São Paulo: Editora da Unesp, Hucitec, 2010b.

. Teoria do romance $I$ : a estilística. Trad. Paulo Bezerra. São Paulo: Editora 34, 2015.

BRAIT, B.; PISTORI, M. H. A produtividade do conceito de gênero em Bakhtin e o Círculo. Alfa, São Paulo, n. 56, p. 371-401, jul./dez. 2012.

CAMPOS, L. S. Evangélicos, pentecostais e carismáticos na mídia radiofônica e televisiva. Revista USP, São Paulo, n. 61, p. 146-163, mar./maio 2004.

CAMPOS JÚNIOR, Luís de Castro. Pentecostalismo. São Paulo: Ática, 1995.

CHARAUDEAU, P. Discurso das mídias. Trad. Angela S. M. Correa. São Paulo: Contexto, 2010.

DEBORD, Guy. A sociedade do espetáculo. Rio de Janeiro: Contraponto, 2003.

DUFOUR, Dany-Robert. A arte de reduzir as cabeças: sobre a nova servidão na sociedade ultraliberal. Trad. Sandra Regina Felgueiras. Rio de Janeiro: Companhia de Freud, 2005.

. O divino Mercado: a revolução cultural liberal. Trad. Procópio Abreu. Rio de Janeiro: Companhia de Freud, 2008.

FARACO, Carlos Alberto. Linguagem \& diálogo: as ideias linguísticas do círculo de Bakhtin. São Paulo: Parábola, 2009.

FAUSTO NETO, Antônio. A religião do contato: estratégias discursivas dos novos "templos midiáticos”. Contemporânea, Rio de Janeiro, v. 2, n. 2, p. 139-168, dez. 2004.

GOMES, Pedro Gilberto. Da igreja eletrônica à sociedade em midiatização. São Paulo: Paulinas, 2010.

GRILLO, Sheila. Esfera e campo. In: BRAIT, Beth (Org.). Bakhtin: outros conceitos-chave. 2. ed. São Paulo: Contexto, 2012. p. 133-160.

LIPOVETSKY, Gilles. A felicidade parado$x a l$ : ensaio sobre a sociedade do hiperconsumo. Trad. Patrícia Xavier. Lisboa: Edições 70, 2014a.

O capitalismo estético na era da globalização. Trad. Luis Filipe Sarmento. Lisboa: Edições 70, 2014b.

O império do efêmero: a moda e seu destino nas sociedades modernas. Trad. Maria Lucia Machado. São Paulo: Companhia das Letras, 2009.

MARIANO, Ricardo. Os neopentecostais e a teologia da prosperidade. Novos estudos, São Paulo, n. 44, p. 24-44, mar. 1996.

MARIANO, R.; PIERUCCI, A. F. O envolvimento dos pentecostais na eleição de Collor. Novos estudos, São Paulo, n. 34, p. 92-106, nov. 1992.

MEDVIÉDEV, P. N. O método formal nos estudos literários: introdução crítica a uma poética sociológica. Trad. Sheila Grillo e Ekaterina Américo. São Paulo: Contexto, 2012.

MORAES, G. L. Idade mídia evangélica no Brasil. São Paulo: Fonte Editorial, 2010. 
PIERUCCI, A. F. O. Representantes de Deus em Brasília: a bancada evangélica na constituinte. Ciências Sociais Hoje, São Paulo, n. 11, p. 104-32, 1989.

RIBEIRO, Kelli da Rosa. Bivocalização e plurivocalização no culto televisivo show da fé: tensão entre fé, Mercado e publicidade. 2015, $261 \mathrm{f}$. Tese (Doutorado em Letras). Pontifícia Universidade Católica do Rio Grande do Sul.

SOBRAL, Adail. Do dialogismo ao gênero: as bases do pensamento do Círculo de Bakhtin. Campinas, SP: Mercado de Letras, 2009.

TELES, F. G. Teologia franciscana da pobreza evangélica. Âncora: Revista Digital de Estudos em Religião, São Paulo, v. 1, p. 62-82, maio 2006 .

VOLOCHINOV, V. N. (BAKHTIN, M.). A palavra na vida e na poesia: introdução ao problema da poética sociológica. In: BAKHTIN, Mikhail (Org.). Palavra própria e palavra outra na sintaxe da enunciação. Trad. Allan Pugliese, Camila Scherma, Carlos Turati, Fabrício Oliveira, Marina Figueiredo, Regina Silva e Valdemir Miotello. São Carlos: Pedro \& João editores, 2011. p. 147-181. 